\title{
Luis Díaz Viana, Miedos de hoy. Leyendas urbanas y otras pesadillas de la sobremodernidad. Salamanca, Editorial
} Amarante, 2017, $241 \mathrm{pp}$.

Este es un libro complejo y sorprendente que también trata de los miedos de hoy, es decir, trata de ellos en cuanto a pensamientos organizados en narraciones de transmisión oral, pero comienza su fascinante historia mucho antes. Antes del miedo y antes del hombre moderno, cuando la ecuación lugar-memoria-tiempo tenía sentido en sí misma y articulaba nuestras vidas.

El ensayo está organizado en cuatro partes diferenciadas — Las voces de la identidad, Los ecos de la memoria y el desasosiego de la cultura, Los mensajes del miedo, y Cuando los dioses no son necesarios- y rematado con un lúcido epílogo. Comienza desgranando las diferencias (¿diferencias?) entre naturaleza y cultura, para meterse de lleno luego en la naturaleza de la identidad, de la alteridad, y la invención de la tradición en su primera parte. No en vano, el miedo primigenio que nos mueve a todos es siempre un miedo a lo desconocido, a lo otro, al otro, y para saber quién o qué representa ese miedo, hay que indagar en quiénes somos nosotros — con el desasosiego que ello comporta. En la segunda parte, y utilizando los relatos como hilos conductores de temas nuevos y viejos, el autor nos desvela inusitadas conexiones entre el pasado y el presente a través del análisis de antiguos mitos y modernas oralidades juveniles, o nos orienta en el entendimiento de las manifestaciones humorísticas como símbolo de nuestras sociedades y síntoma de sus situaciones políticas.

$\mathrm{Y}$ es en lo que sigue, a partir de la tercera parte, cuando comienza a describir la ruptura temporal de nuestra era, al tiempo que reivindica la actualidad del pasado o la atemporalidad de los miedos del futuro como presagios inciertos. Porque una de las principales tesis sobre las que se asienta este complejo ensayo cultural es que la ecuación lugar-memoria-tiempo, que hasta hace no mucho tiempo articulaba nuestras vidas, ya no sirve de referencia en esta época sobremoderna. Ahora se han globalizado los lugares o han sido desposeídos de su identidad — los no-lugares de que hablaba Augé (1992)—, se han rasgado las conexiones de la memoria con los lugares en los que habitaba, y se ha fracturado nuestro tiempo al discontinuar y cuestionar nuestra relación con el ayer y el mañana, ajenos ya en su presencia omnímoda al escueto presente en que vivimos.

Finalmente, en la última parte se plantea algunas grandes preguntas en relación a las funciones de la ciencia, la tecnología y la religión en nuestro extraño y desencajado mundo actual, y reivindica un papel de relieve para la Antropología como ciencia de comprensión de los cambios y las continuidades, de comprensión de lo nuestro y lo de los otros, y de los diálogos entre todos. Se remata el volumen con una sagaz y penetrante reflexión sobre lo que ha sido considerado como la esencia de lo humano, y sobre cómo ésta ha ido cambiando según cambiaban nuestras sociedades y necesidades.

Pero volvamos al principio. En el principio existe el hombre que nuestra sociedad ha construido como «natural», aunque «lo humano, desde las aportaciones de la antropología aparece más como una condición que como una naturaleza» (22). Es más, «el proyecto humano $[. .$.$] no se reduce a adquirir un lenguaje, sino a aprehender una cultura de la que$ el lenguaje forma parte, y no al revés» (25). Siguiendo este pensamiento, Díaz Viana nos 
expone cómo, a través de nuestra capacidad humana de narrarnos — de ser homo narrans - podemos llegar a ser hombres completos; «ser homínidos es nuestra naturaleza y ser humanos una condición que se ha logrado con el tiempo» (27, énfasis en el original). Y va más allá, planteando algunas de las incómodas cuestiones de nuestro tiempo: desde la humanización de los animales a la deshumanización (tecnológica) de los hombres. Aquí, en este punto, es donde la narración marca la diferencia de lo humano: las historias que contamos, nuestra capacidad de pensarnos y de compartir miedos y anhelos a través de ellas, nos distingue a día de hoy de todos los animales y de todas las máquinas (33), y es bastante probable que esa diferencia no vaya a desaparecer en el futuro próximo.

Y ya puestos, debió de pensar el autor, si vamos a contarnos, vamos a explorar algunas de las retóricas del espacio y del tiempo en la construcción de nuestras propias identidades (41-50). De nuevo, aparecen temas incómodos, liminales, de una actualidad históricamente construida, una buena muestra de nuestros conflictos irresueltos: se habla de la utilización de la historia como argumento de reivindicación territorial, de los estereotipos sobre la «falta de identidad» castellana, de las utilizaciones políticas de la identidad y la otredad que, no por ser totalmente actuales, dejan de tener precedentes antiquísimos, incluso míticos, y se habla de las representaciones etnográficas que nos ofrecen los museos de este tipo, con el objetivo de crear referentes únicos en la representación del espacio, del tiempo y de la memoria. Pero las maneras de contarnos son muchas y, entre ellas, destaca el autor por su ubicuidad y potencia, el mito, la leyenda y el rumor (recuerde el lector las muy actuales fake news, que son tan antiguas como el hombre). Les dedica Díaz Viana una comedida explicación que, sin embargo, resulta tan didáctica como iluminadora, por las certezas que nos aporta y, más aún, por lo muy perturbador que resulta saber la antigüedad de lo que consideramos contemporáneo y la radical actualidad de lo que nos hacía humanos en el principio de los tiempos (88-110). Es la persistencia del lugar en el tiempo (su significación como tal), lo que nos conduce a la memoria y, por tanto, al eventual sentimiento identitario, y al fraude, eventual también, que este sentimiento produce cuando es examinado históricamente; la mencionada fractura de la ecuación lugar-memoria-tiempo.

Y continúa Díaz con las preguntas incómodas, gran parte de las cuáles ya aparecían en trabajos anteriores, aunque aquí se ordenen y conecten para intentar explicarnos nuestros propios miedos. Continúa también con las respuestas parciales (no hay respuestas finales) y los giros inesperados en los que nos sitúa la sobremodernidad: lo que tantas veces hemos estudiado como pasado sigue plenamente inserto en nuestro presente; lo que entendíamos como lejano, o rural, o antiguo, no solo sigue pasando a nuestro lado, ahora mismo, sino que ya pasa en cualquier lugar, a la vez; aquello que afectadamente reducíamos a la memoria de los más mayores - el folklore - tiene infinitos, aunque diferentes, desarrollos entre los adolescentes de cualquier parte del mundo, en cualquier cultura y tiempo (111-123); y el humor o el chiste no son objetos menores de investigación, sino constructos que nos revelan importantes matices contextuales y políticos de la actualidad, porque no hay creación de folklore, chistes incluidos, que siga siendo transmitida sin significar nada (Dundes 1987: vii; citado en 130).

Y tras estos prolegómenos, extensos pero necesarios, se zambulle Díaz en la poética popular del desasosiego, en el miedo y en el miedo al miedo, el miedo a lo que puede llegar a ocurrir y a cómo podemos reaccionar ante ello. Si las cuestiones planteadas hasta el momento podían resultar problemáticas, aunque pertinentes en todo caso, ahora el autor nos presenta el camino que nos lleva al horror, a lo aterrador, a lo potencialmente 
posible aunque indeseable, y nos lo presenta a través de la transmisión oral actual. Lo antiguo y legendario sigue formando parte, también, de nuestros delirios más actuales; los miedos de hoy se actualizan y renuevan las más arcaicas y lejanas tradiciones del terror (157-167). Y es que las leyendas de hoy, los miedos de hoy, no dejan de ser, como anuncia el autor en el subtítulo del libro «pesadillas de la sobremodernidad», porque el tiempo está descoyuntado, porque no son más que representaciones de nuestra desorientación espacio-temporal (169).

Aquí, el análisis de las similitudes y diferencias entre las narraciones de ayer y de hoy nos lleva a dos conclusiones igualmente perturbadoras: por un lado sigue habiendo leyendas - que ahora son, también, urbanas - porque sigue habiendo una necesidad de articular nuestros miedos comunes en narraciones contemporáneas; es decir, en algunas cosas no hemos cambiado nada a lo largo de los últimos siglos. Y por otro lado, todo ha cambiado, porque se ha transformado la manera en que se concibe el espacio y el tiempo, de modo que «estaría ya irremisiblemente alterada esa capacidad de recordar otros tiempos desde un mismo espacio al que se pertenece» (174), es decir, «lo importante de la narración ya no está en esa ligazón fuerte de lugar-identidad-tiempo» (175). En este sentido, nos recuerda el autor, por su pertinencia en todo tiempo, a Sontag, una de las pensadoras que mejor captó, con inquietante perspicacia, el palpitar renovador de las culturas urbanas y sus varias consecuencias ético-estéticas en la época posmoderna, posttradicional o sobremoderna. Sus agudas observaciones sobre los cambios $-\mathrm{y}$ las permanencias - que el siglo XX nos presentaba — hasta la implosión post-democrática del cambio de siglo, al menos - tienen muchos paralelismos con el libro del que aquí se habla. Si en Sontag (1969) las observaciones eran minuciosas en lo local y aterradoramente certeras en lo global, en Díaz Viana la sorpresa viene de la cercanía con la que trata nuestros temas, aquellos que nos identifican, y la precisión de cirujano con la que los disecciona hasta hacerlos universales y eternos.

«El mundo dislocado», «las arduas narrativas de la desarticulación», «el paisaje en escombros de la sobremodernidad»... los sugerentes títulos utilizados por el autor en los siguientes apartados nos llevan por un tortuoso camino de desesperanza con final abierto. Todo nos conduce a una antropología como ciencia necesaria, como camino de explicación de los mitos del futuro (tiempos), del pasado (memorias) y del presente (lugares). Porque, como resalta Díaz Viana,

se trata, finalmente, de presentar alternativas a esa triple negación (de no-tiempo, de nolugar, y de no-memoria), que la sobremodernidad nos plantea [...] y hemos denunciado ese vértigo que produce correr sin una dirección clara y mirando solo hacia adelante. (205)

En la necesidad de plantear alternativas es donde se hace pertinente la vuelta a una antropología que sea necesaria, relevante, una antropología «urgente», «de guardia», que nos ayude a transitar por el proceloso mundo de los cambios bruscos en los modos de vida, en los saberes relevantes o en las transformaciones globales, sin que el miedo nos paralice (211). Una antropología que, sin embargo, sea consciente de nuestras limitaciones como humanos, «porque progresar no es querer cambiarlo todo» (213, énfasis en el original).

Se cierra el volumen con otra perspicaz reflexión sobre lo que - creemos - nos hace humanos, y sobre cómo nuestras concepciones sobre ello han ido cambiando a lo largo de la historia. Todo cambia y todo permanece. Es, en definitiva, un cierre inquietantemente adecuado para un volumen fruto de una reflexión madura sobre nuestros 
miedos, siempre renovados, y las variadas formas que utilizamos para contárnoslos, pero también sobre muchos de los temas que han preocupado al autor a lo largo de su dilatada y fructífera carrera y que tienen en común la transmisión oral y su capacidad articuladora en todo tiempo. Porque muchas de las leyendas son nuevas, pero los miedos que articulan y esconden son tan antiguos como el mundo.

\section{BIBLIOGRAFÍA CITADA}

Auge, Marc (1992): Non-lieux, introduction à une anthropologie de la surmodernité, París, Le Seuil. [Los 'no lugares', espacio del anonimato. Una antropología de la sobremodernidad, trad. Margarita Mizraji, Barcelona: Editorial Gedisa, 1998]

DuNDES, Alan (1987): Cracking Jokes. Studies of Sick Humanor Cycles and Stereotypes, Berkeley, CA, Ten Spedd Press.

SonTAG, Susan (1969): Styles of radical will. New York. Farrar, Straus and Giroux. [Estilos radicales, trad. Eduardo Goligorsky, Barcelona: Muchnik Editores, 1985]

Susana Asensio Llamas

(Consejo Superior de Investigaciones Científicas) 